$12^{\text {th }}$ International Conference on Structural Analysis of Historical Constructions SAHC 2020

P. Roca, L. Pelà and C. Molins (Eds.)

\title{
NUMERICAL INVESTIGATIONS FOR ASSESSING THE SEISMIC PERFORMANCE OF MULTI-TIERED NEPALESE TEMPLES
}

\section{MIRKO PEJATOVIC ${ }^{3}$, VASILIS SARHOSIS ${ }^{2}$, GABRIELE MILANI ${ }^{1}$}

\author{
${ }^{1}$ Department ABC, Technical University of Milan \\ Piazza Leonardo da Vinci 32, Milan 20133, Italy, gabriele.milani@polimi.it \\ ${ }^{2}$ School of Civil Engineering, University of Leeds \\ LS2 9JT, Leeds, UK, v.sarhosis@leeds.ac.uk \\ ${ }^{3}$ Department of Architecture, Built Environment and Construction Engineering, \\ Technical University of Milan
}

Piazza Leonardo da Vinci 32, Milan 20133, Italy, mirko.pejatovic@polimi.it

Keywords: Nepal earthquake, Cultural heritage buildings, Seismic damage, Masonry, Finite element method, Numerical modelling

\begin{abstract}
In this study, the seismic performance of old multi-tiered temples in Nepal has been addressed using three different computational approaches, including a) linear elastic; b) nonlinear static; and c) nonlinear dynamic analyses. Also, a sensitivity study was undertaken to understand the influence of wall thickness and height of Nepalese temples on their seismic behavior. Vertical oscillating modes using the elastic response spectrum of the Nepalese Building Code were obtained using linear analysis. Nonlinear static analysis (NLSA) were implemented to obtain the load carrying capacities of different in geometry temples e.g. different thickness of central core walls and number of tiers. Additionally, nonlinear dynamic analysis (NLDA) using the Finite Element Method (FEM) were performed to evaluate the characteristic tensile damage patterns. The results comparatively indicate the weakest zones depending on wall thickness, central core slenderness, opening distribution, box-like confinement, vertical misalignment of walls and so forth. Also, the results of the NLDA affirm high vulnerability of the multi-tiered temples showing extensive cracks at relatively low peak ground accelerations. It is anticipated that outcomes of this study can help practicing engineers to understand how these structures behave when subjected to seismic loads and provide insights towards their strengthening and retrofitting.
\end{abstract}

\section{INTRODUCTION}

The preservation of cultural heritage is a crucial issue all over the world, such as Nepal, whose territory is characterized by both significant seismicity and presence of a large amount of monumental masonry constructions of major historical importance, such as temples. Despite the importance of such kind of structures, research has recently been more focused on 
architectural heritage buildings belonging to Mediterranean countries (industrially developed but at the same time in high seismicity regions), and hence on masonry churches (e.g. [1], towers [2, 3], etc. The lessons learnt from previous earthquakes together with deep study of structural weaknesses of monumental buildings lead to proper intervention design and their conservation [4].

Multi-tiered temples (See Figure 1) built in Nepal are traditional and monumental structures which apart from their architectural significance, present both valuable historic and archaeological importance. However, the 2015 Gorkha Earthquake and its related aftershocks dramatically altered the iconic historic structures in Nepal. According to Nepal's Department of Archaeology, around 750 heritage structures of significant cultural and religious value (e.g. temples and shrines) were affected. Discussions to place it on UNESCO's List of "World Heritage in Danger" are already underway.
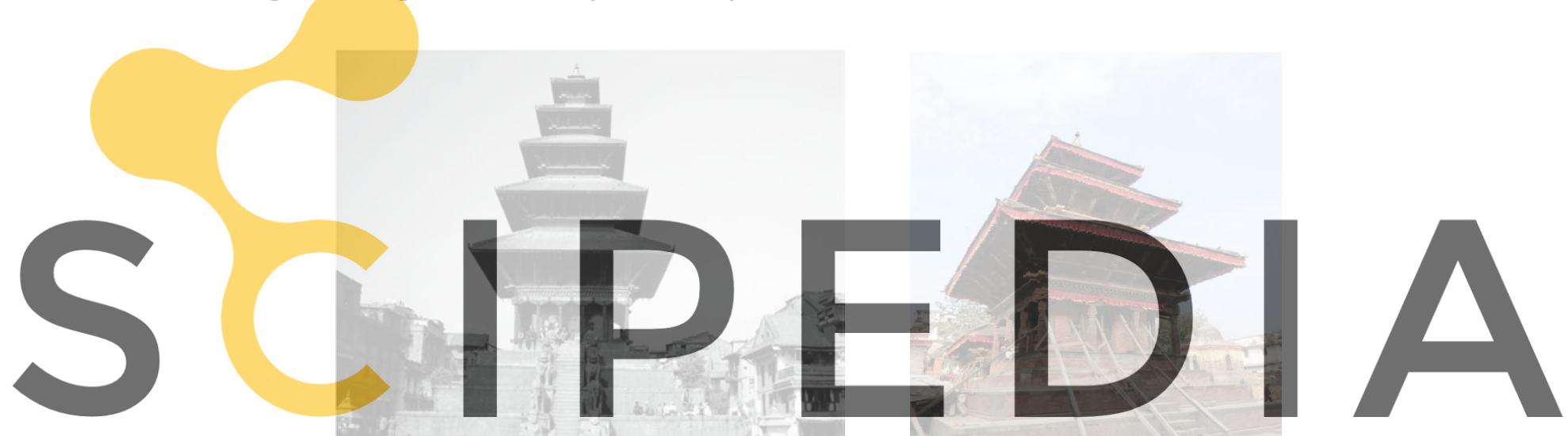

In particular, Nepalese multi-tiered temples are characterized by a combination of brickwork constructed with mud mortar. These structures are characterized by: a) geometric symmetry; b) asymmetry in mass distribution along the height of the structure i.e. the mass of the structure increases from top to bottom; and c) the temples are resting on a huge and massive plinth (or exposed foundation) [7].

Modelling multi-tiered Nepalese temples is a very complex task due to numerous uncertainties and lack of accurate material characterization. Aligned with the UN Sustainable Development Goal 11.4 "Strengthen efforts to protect and safeguard the world's cultural and natural heritage" and Nepal's national strategy for disaster risk management (2009) the research presented herein aims to assess seismic performance of old multi-tiered temples in Nepal using different computational approaches, including: a) linear elastic; b) nonlinear static; and c) nonlinear dynamic analyses. A sensitivity study is also undertaken to understand the influence of wall thickness and height of Nepalese temples on their seismic behavior. 


\section{NUMERICAL MODELING OF MULTI-TIERED TEMPLES}

Initially, elastic models of the Gopinath and Nyatopol temples were developed and modal analysis were undertaken in order to verify the dynamic properties of the structures. Eccentric effects of the walls and the top of the temples were considered. Numerical models based on the macro-modelling approach have been developed in which masonry is represented using the Concrete Damaged Plasticity law (CDP), available in ABAQUS software. In addition, for the development of the numerical models it was assumed that: a) the plinth is rigid; b) the floors are rigid, since timber beams are attached to walls; c) the roof is considered as non-structural element; and d) the weight of the wooden pinnacle is neglected at the very top since its weight is small relatively to the other parts of the structure.

\subsection{Dynamic identification of the multi-tiered temples}

Initially, the mechanical properties of the masonry material to be inputted into the numerical model calibrated. Material calibration was performed by dividing the structure into three regions. A different modulus of elasticity has been selected for each case (see Figure 2).
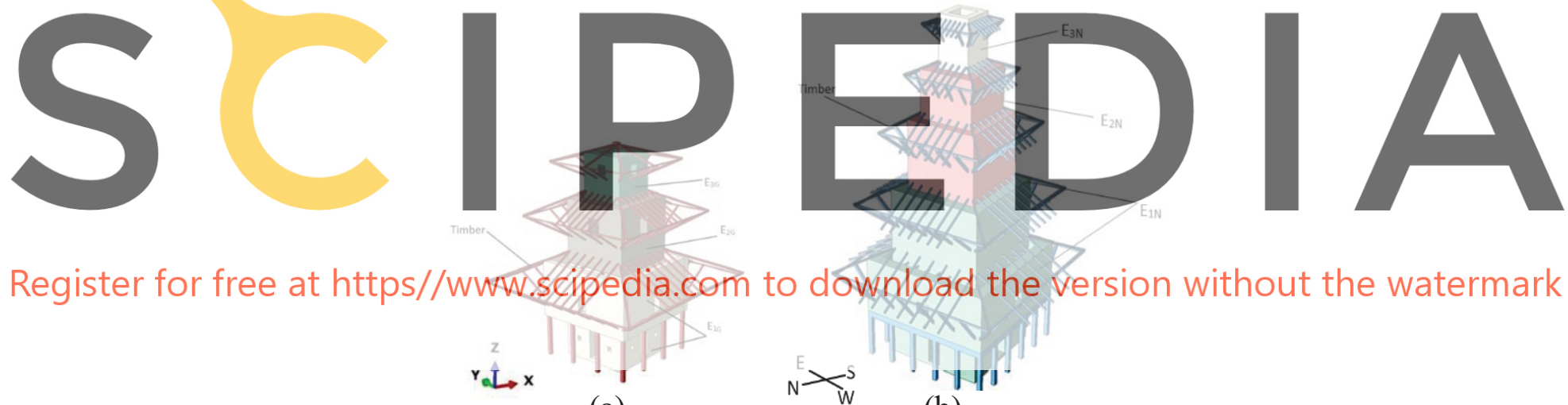

(a)

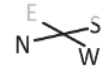

$\tau_{W}^{S}$

Figure 2 - Three dimensional FE models of: (a) Gopinath and (b) Nyatopol temples. Different colors represent the different modulus of elasticity assigned to the models (see also Tables 2 and 3 )

The numerical frequencies obtained from the numerical model are less than $5 \%$ different to the ones obtained experimentally. Calibrated modes for both temples are the first three main flexural modes in one of the principal directions (see Table 1 and

Table 2).

Table 1 - Calibration of parameters for Gopinath temple $-\mathrm{E}_{1}=140 \mathrm{MPa} ; \mathrm{E}_{2}=141 \mathrm{MPa} ; \mathrm{E}_{3}=140 \mathrm{MPa}$

\begin{tabular}{cccc}
\hline Mode & Direction & Numerical freq. $(\mathrm{Hz})[6]$ & Error $(\%)$ \\
\hline Mode 1 & Horizontal & 1.90 & -5.00 \\
Mode 4 & Horizontal & 4.37 & -2.88 \\
Mode 8 & Horizontal & 7.77 & 5.00 \\
\hline
\end{tabular}


Table $2-$ Calibration of parameters for Nyatopol temple $-\mathrm{E}_{1}=265 \mathrm{MPa} ; \mathrm{E}_{2}=245 \mathrm{MPa} ; \mathrm{E}_{3}=245 \mathrm{MPa}$

\begin{tabular}{cccc}
\hline Mode & Direction & Numerical freq. (Hz) [5] & Error (\%) \\
\hline Mode 1 & Horizontal & 1.60 & -4.59 \\
Mode 4 & Horizontal & 3.91 & -0.98 \\
Mode 7 & Horizontal & 6.67 & 4.90 \\
\hline
\end{tabular}

\section{LINEAR ANALYSES}

Linear analysis of the temples were undertaken to understand the local dynamic response and identify the possible local failure mechanisms that can occur before their global collapse. In the case when the timber links were not present (non-existing as structural elements or broken due to excess of load carrying capacity), the external walls were not restrained along the upper edge and unable to resist lateral loads alone. This may lead to overturning as a result of out-ofplane failure associated with extensive cracking pattern in the vertical direction at the corners.

Global dynamic response of the temple is significantly influenced by oscillations in Z

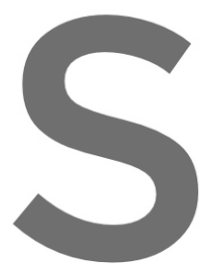
direction that have nore or less substantial effective mass and response spectrum. Thi being eccentrically pos the masonry walls v static and dynamic the masonry core being applied as patch loads

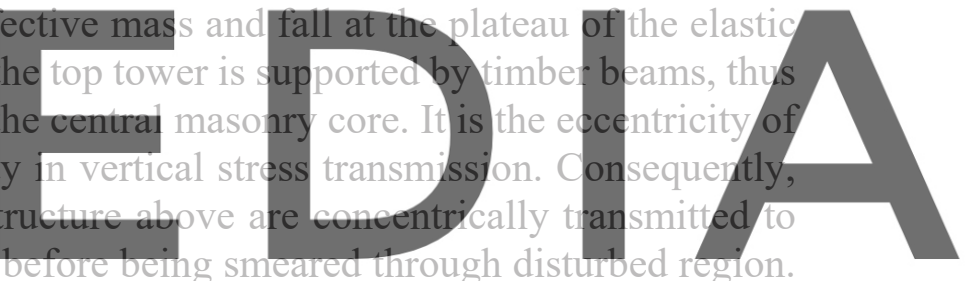

This effect can cause local crushing of masonry material at the points of stress concentration.

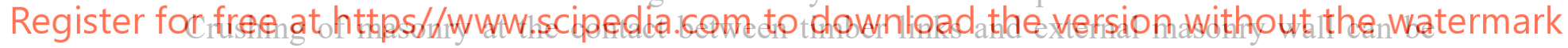
observed from the outcomes of the pushover analysis performed. The results indicate crack pattern due to excess stress concentrations.

\section{PUSHOVER ANALYSIS}

A macro-element model has been developed and the concrete damage plasticity model (CDPM) [8] implemented in ABAQUS has been used. Figure 3 shows actual non-linear behavior of masonry in both tension and compression.

Comparative pushover analyses have been performed on Gopinath and Nyatopol temples by varying their height and wall thicknesses. The geometric parametric configuration used as part of this study is shown in Figure 4.

Figure 4 shows the different geometrical configurations of temples obtained by the variation of two main parameters: (a) the total height $(\mathrm{H})$ of temple; and (b) the thickness of the wall (d) at the central masonry core at the ground level. 


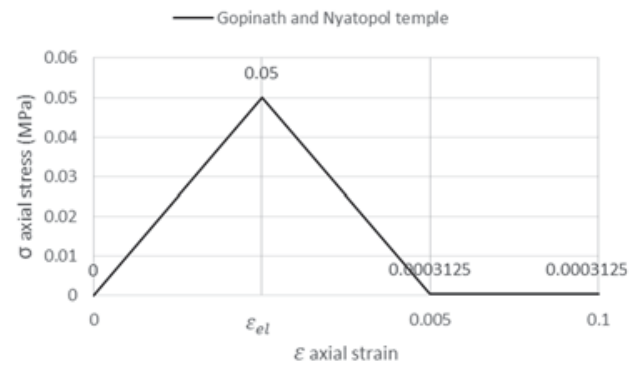

(a)

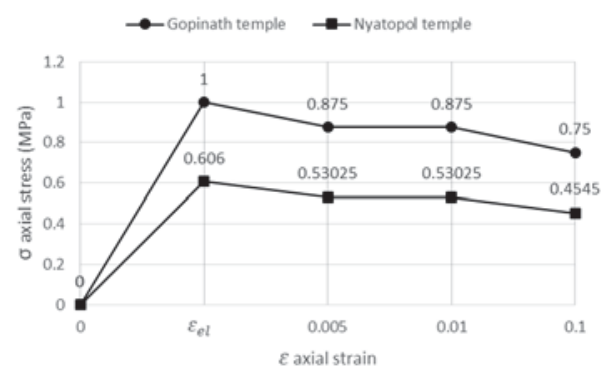

(b)

Figure 3 - Non-linear uniaxial stress-strain actual behavior of masonry ((a) in tension; (b) in compression) [9].
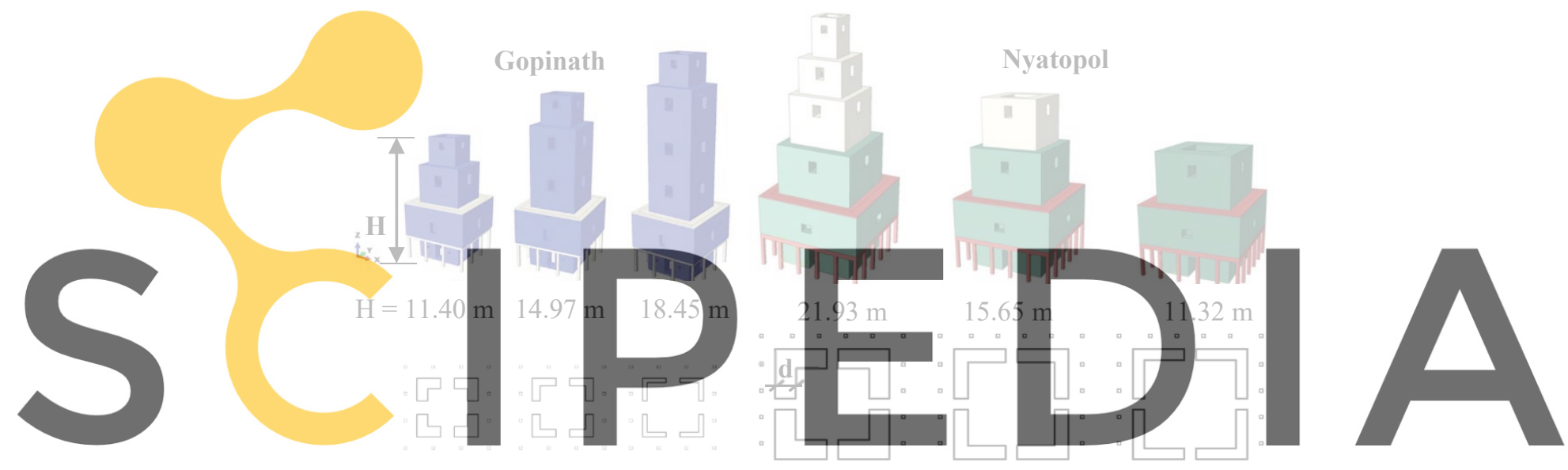

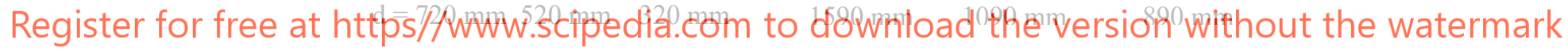

Figure 4 - Gopinath and Nyatopol temples: Different heights $(\mathrm{H})$ and thicknesses $(\mathrm{d})$ of masonry walls

Figure 5 and Figure 6 show the capacity curve diagrams and tensile damage patterns of the corresponding structures in three-dimensional view. Capacity curves give information about variation of ultimate base shear in X direction limited by black circles at the position of ultimate displacements, which are evaluated according to the Italian Guideline for Built Cultural heritage as six times the displacements at elastic limit [10].

Tensile damage patterns consist of cracks at the beginning of each floor (see Figure 5). This is evident for the Nyatopol temple (see Figure 6) which possesses characteristic pyramidal configuration and abrupt change of stiffness at each tier with vertical misalignments of walls of central masonry core. Taller structures behave similarly to towers forming plastic hinges at its bases accompanied with horizontal and diagonal cracks. Figure 5 shows that stocky temples experience shear failure, while in the case of slender temples flexural failure with formation of plastic hinge at the level of second floor was observed. The intermediate cases which were investigated found to undergo a combination of shear and flexural behavior at collapse.

Figure 6 shows that Nyatopol temples with varied geometrical parameters show similar cracking trends. Finally, in both groups of temples progressive change of failure mechanism is 
evident, passing from shear failure for stocky to flexural failure for slender temples. Conveniently established failure mechanisms for certain typology of structures are crucial step towards simplified analysis using pre-assigned failure modes, which must be justified by nonlinear dynamic analysis.

The ultimate base shear decreases as the thickness of walls of central masonry core decreases, but particularly decreases in the case of increase of the total height. In particular, for the case of the Gopinath temple with fixed values of thickness at the ground floor, the total base shear at ultimate decreases from $43 \%$ to $48 \%$ when one floor was added and from $63 \%$ to $68 \%$ when two floors were added. In addition, in the case of temples with fixed heights, the base shear drop ranges between $9 \%$ and $13 \%$ when the thickness of the walls was reduced by 200 $\mathrm{mm}$ and from $21 \%$ to $32 \%$ when the reduction was $400 \mathrm{~mm}$. The blue color stands for undamaged structural regions while the red color indicates fully damage regions. Control points are denoted at each structure.

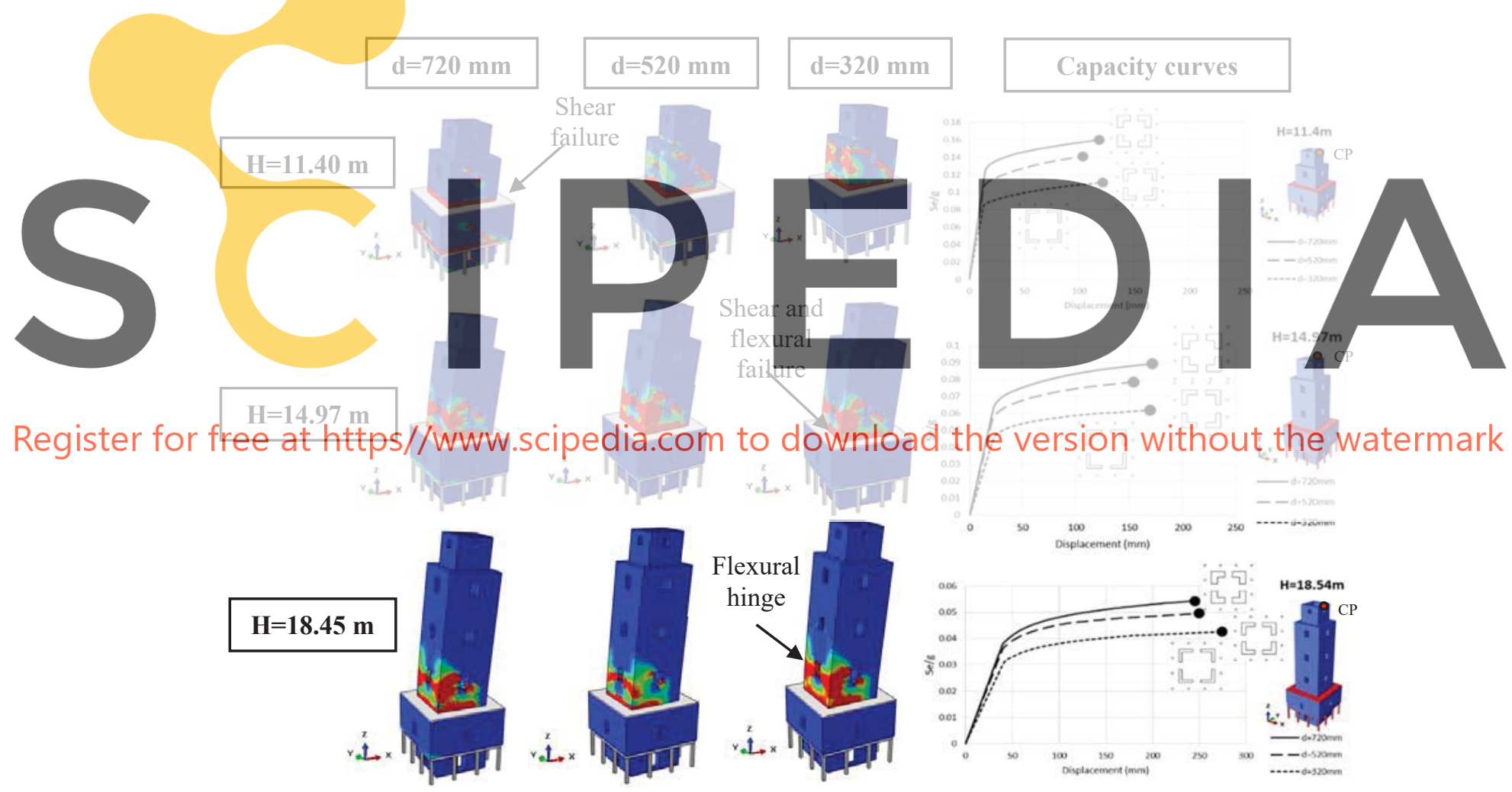

Figure 5 - Tensile damage patterns and capacity curves for Gopinath temple with varied thickness at the ground floor $\mathrm{d}=720 \mathrm{~mm}, \mathrm{~d}=520 \mathrm{~mm}$ and $\mathrm{d}=320 \mathrm{~mm}$ and varied heights $\mathrm{H}=11.40 \mathrm{~m}, \mathrm{H}=14.97 \mathrm{~m}$ and $\mathrm{H}=18.54 \mathrm{~m}$

Regarding variation of the total height, similar trend can be observed in Nyatopol temples, but oppositely with respect to the first group of temples (if the height is reduced then the ultimate base shear increases). However, for the second group of temples, thickness reduction has beneficiary effect on the ultimate base shear expressed as a function of gravity acceleration 
$(\mathrm{g})$. The reason is that structural weight becomes strongly reduced which has a more dominant influence on the growth of the ratio $\mathrm{V} / \mathrm{W}$.

Regarding Nyatopol temple with fixed values of wall thickness at the ground floor, the total base shear at ultimate increases from $26 \%$ to $103 \%$, if the two last floors were removed. Also, when three floors removed then the total base shear at ultimate increases from $72 \%$ to $161 \%$. If the heights were kept constant and the thickness of the wall is equal to $500 \mathrm{~mm}$, then the total base shear at ultimate ranges from $4 \%$ to $12 \%$, while when the wall thickness is equal to 700 $\mathrm{mm}$, the total base shear decreases from $12 \%$ to $26 \%$.

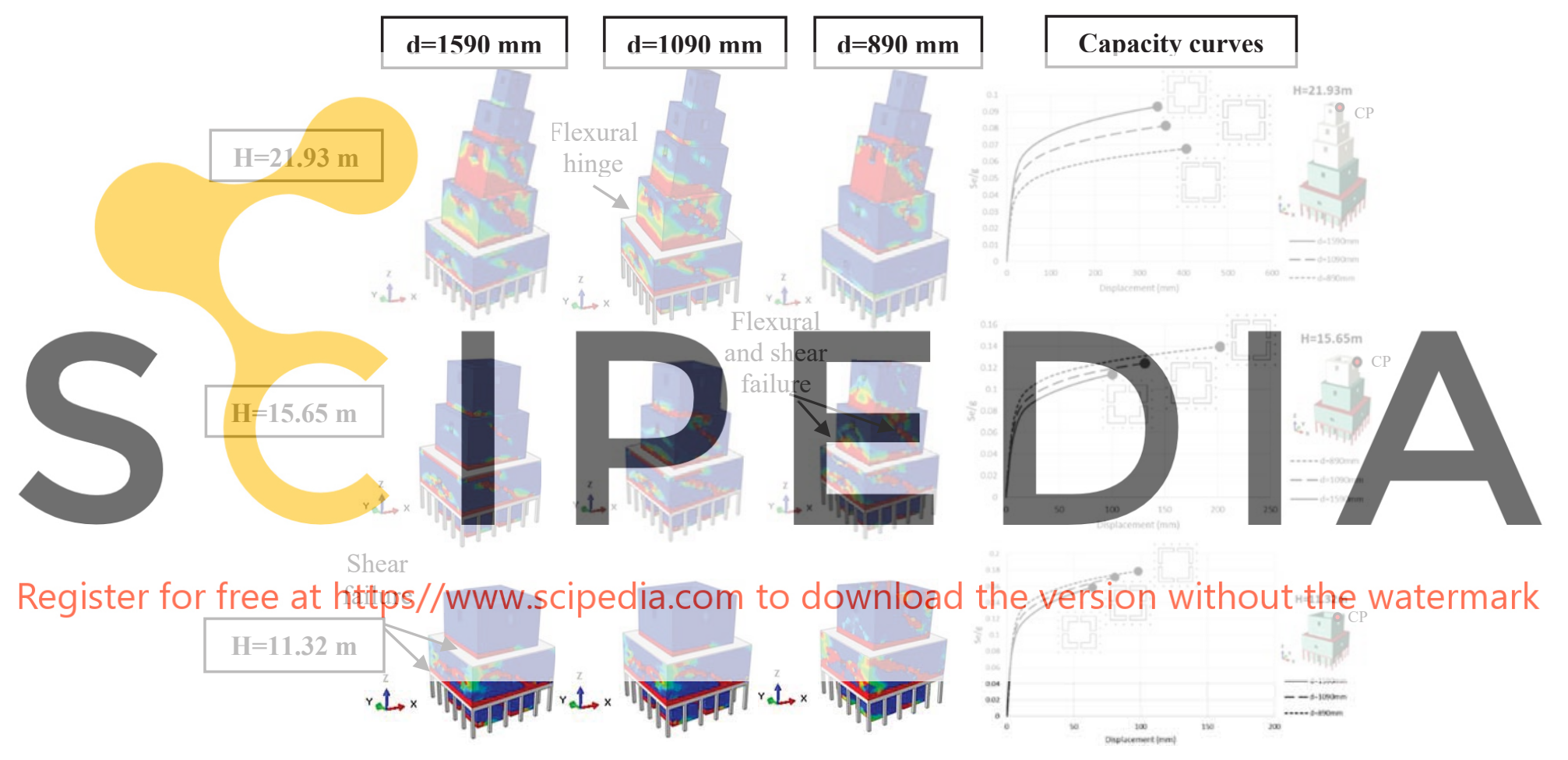

Figure 6 - Tensile damage patterns and capacity curves for Nyatopol temple with varied thickness at the ground floor $\mathrm{d}=1590 \mathrm{~mm}, \mathrm{~d}=1090 \mathrm{~mm}$ and $\mathrm{d}=890 \mathrm{~mm}$ and varied heights $\mathrm{H}=21.93 \mathrm{~m}, \mathrm{H}=15.65 \mathrm{~m}$ and $\mathrm{H}=11.32 \mathrm{~m}$

\section{NONLINEAR DYNAMIC ANALYSIS (NLDA)}

Time-history nonlinear analyses were performed using spectrum compatible for the location of Kathmandu Valley accelerogram as shown in Figure 7. This spectrum compatible accelerogram was used mainly for comparative reasons and to assess the damage and preliminary load carrying capacity evaluation of the temples under consideration. 


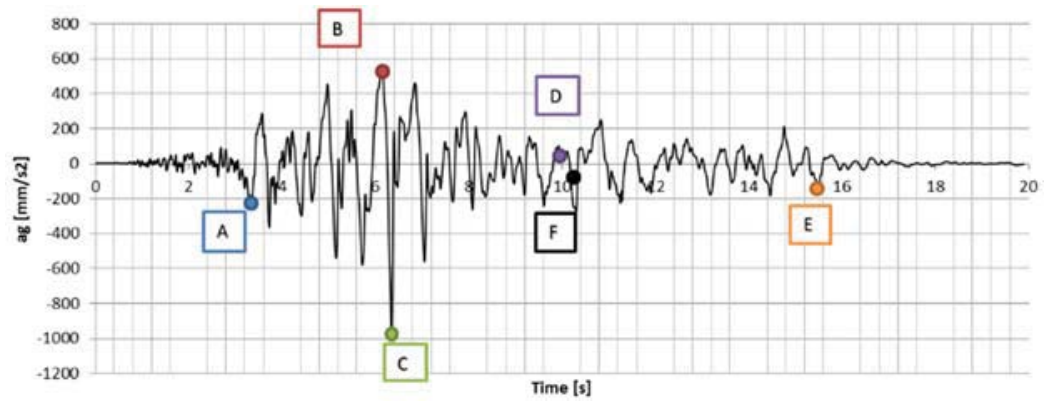

Figure 7 -Spectrum compatible accelerogram PGA=0.1 g

In the NLDA, the peak ground acceleration has been take as $0.1 \mathrm{~g}$ for all 18 structures in each group of temples in order to compare tensile damages. In other words, the analysis was related to comparative damage analysis of two groups of temples with different dynamic responses under the uniform seismic recording applied in $\mathrm{X}$ direction for each temple.

Figure 8 shows the tensile damage patterns and time history of relative drift for the first group of temples. Relative drift has been defined as the displacement normalized with the total height, expressed in percentages. When drift at the top of the structure is greater than $0.8 \%$, the

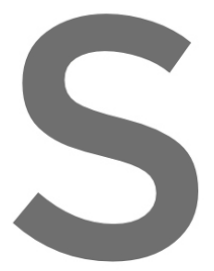
structure fails. From $11.40 \mathrm{~m}$, damages are at the level of the sec

For the structures added in the original the ones observed in the
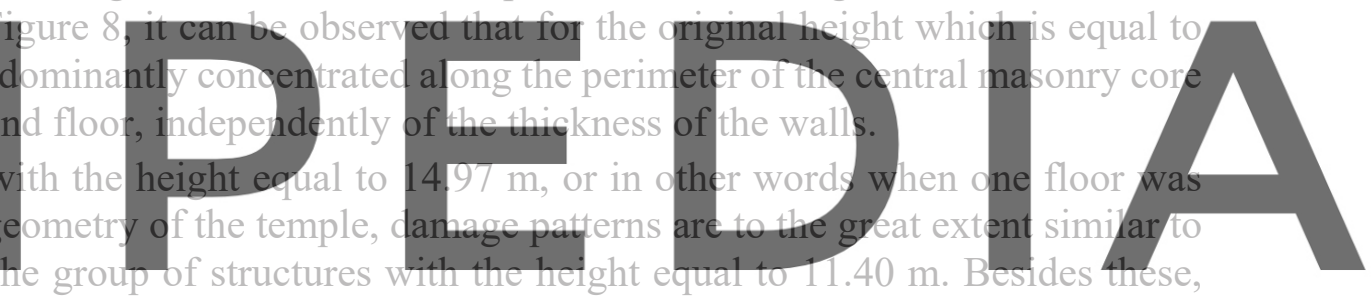

there are inclined damages in the case with the thickness of $320 \mathrm{~mm}$ which corresponds to

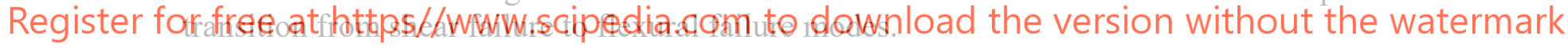

In the case when the height of the temple was equal to $18.54 \mathrm{~m}$, damages migrate at the level of the lowest window openings. Cracks stant from the end of the window openings and propagate to the top, allowing the upper part of the temple to overturn. The two temples with $18.54 \mathrm{~m}$ height experience incipient collapse (drift surpasses $0.8 \%$ of the total height) with overturning of the tower-like upper part, which can be observed in the final row of Figure 8 . Evidently, NLDA shows that plastic hinges for the most slender Gopinath temples occur at the level of the lowest set of window openings, while in pushover analysis overturning takes place around the hinge at the level of second floor.

Figure 9 shows that in stockier structures of the second group of temples, various damage patterns that precede shear failures of entire structural parts (exterior walls and walls of central masonry core) are visible. However, Nyatopol temple with original height which is equal to $21.93 \mathrm{~m}$ is characterized by vertical misalignments and thickness reduction of walls of central masonry core at each floor. These are the reasons for these zones to be the weakest in the structure, which can be justified observing concentration of damages (see the first row of Figure 9). However, certain closed crack patterns in the shape of ellipse are visible from the side perpendicular to ground motion direction. That is the consequence of oscillations of the wall free surface which is far from its constraint zones. These cracks are particularly pronounced in 
the case of the smallest thickness of the base wall which equals $890 \mathrm{~mm}$. This is in opposition with the damage maps obtained by pushover analysis, which forces flexural failure at each level. The reason is irregular pyramidal configuration of the structures with progressive reduction of cross section along the height. Such irregular configuration induces more shear resistance in its behavior than regular slender configuration leading to shear failures of certain structural parts.

Consequently, unlike towers with simple and regular geometry, seismic performance assessment of Nepalese temples with numerous irregularities cannot be evaluated by applying pushover analysis, hence more accurate NLDA is necessary for the evaluation of the dynamic behavior of such temples. This comparative damage analysis shows that one has to be particularly careful while choosing analysis method in order to obtain convenient results. Finally, reliable results are of the utmost importance for implementing intervention strategies which are essential for the preservation of such invaluable built cultural heritage.
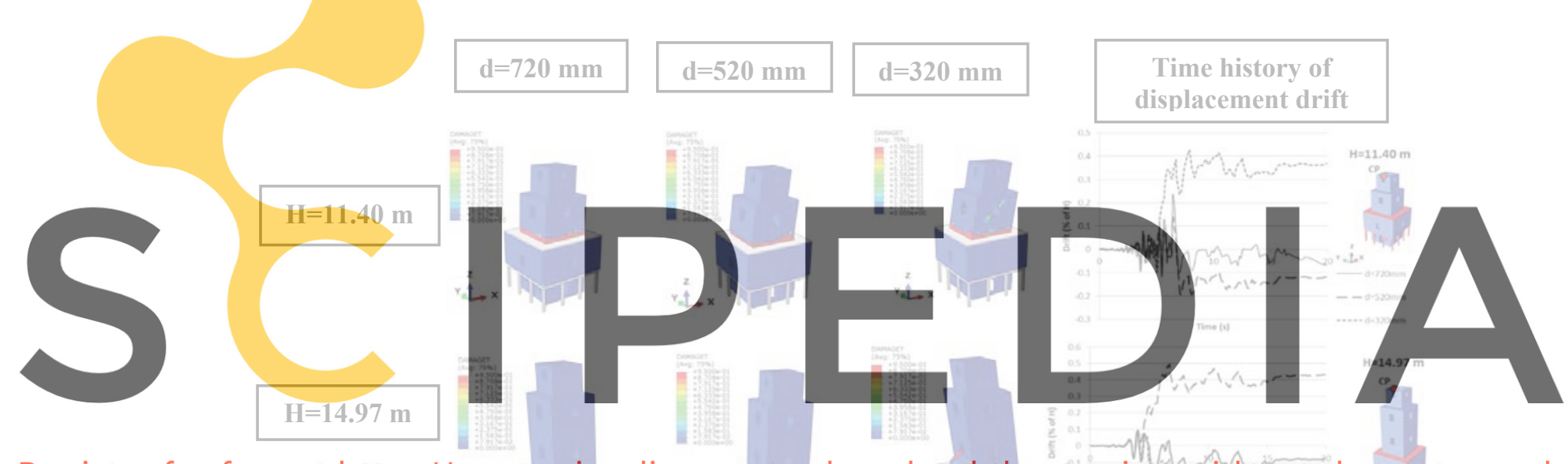
Register.
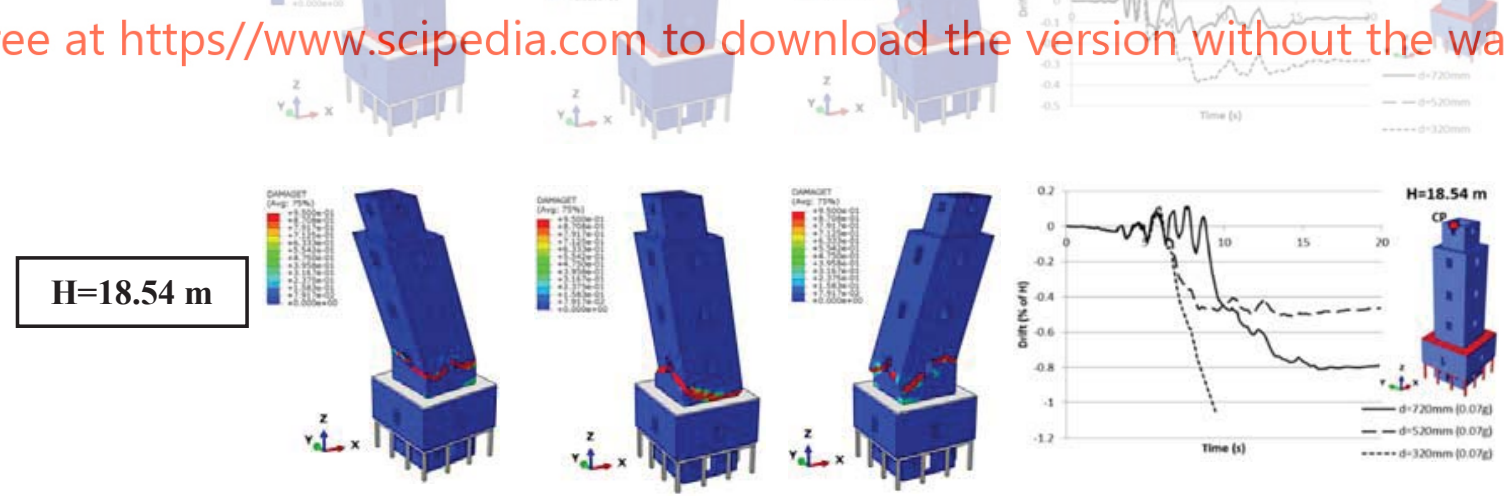

Figure 8 - Final tensile damage patterns and time history of displacement drift of the control points for Gopinath temple with varied thickness $d=720 \mathrm{~mm}, \mathrm{~d}=520 \mathrm{~mm}$ and $\mathrm{d}=320 \mathrm{~mm}$ at the ground floor and varied height $\mathrm{H}=11.40 \mathrm{~m}, \mathrm{H}=14.97 \mathrm{~m}$ and $\mathrm{H}=18.54 \mathrm{~m}$

A comparative analysis was performed assuming stiff and flexible floors at second floor. Two extreme examples in terms of global structural slenderness investigated: a) Gopinath temple with height equal to $18.54 \mathrm{~m}$; and b) Nyatopol temple with $11.32 \mathrm{~m}$ of the height with 
varied thickness. The main goal was to prove that failure mechanism which occurs in slender temples does not depend on the aforementioned assumption. The reason is the fact that tensile damages are concentrated at the section which is weakened by the window openings and that the structure has characteristic flexural failure mechanism.

For the temples with height equal to $18.54 \mathrm{~m}$, damages were dominantly concentrated along the perimeter of the central masonry core, forming a flexural failure mechanism for all three different thicknesses investigated. Additionally, incipient collapse situation was reached, which was visible by looking at the amount of drift at the control point at the top of the temples.

For the temples with thickness of the walls (d) equal to $720 \mathrm{~mm}$, cracks initiated at the lowest set of window openings, while at the second floor there was a slight indication of damage. Lowintensity damages can be observed at re-entrant corners of the lowest windows. In the case of wall thickness equal to $520 \mathrm{~mm}$, crack pattern was partially flat over the second floor onset and started to be inclined towards the corners of the window opening.

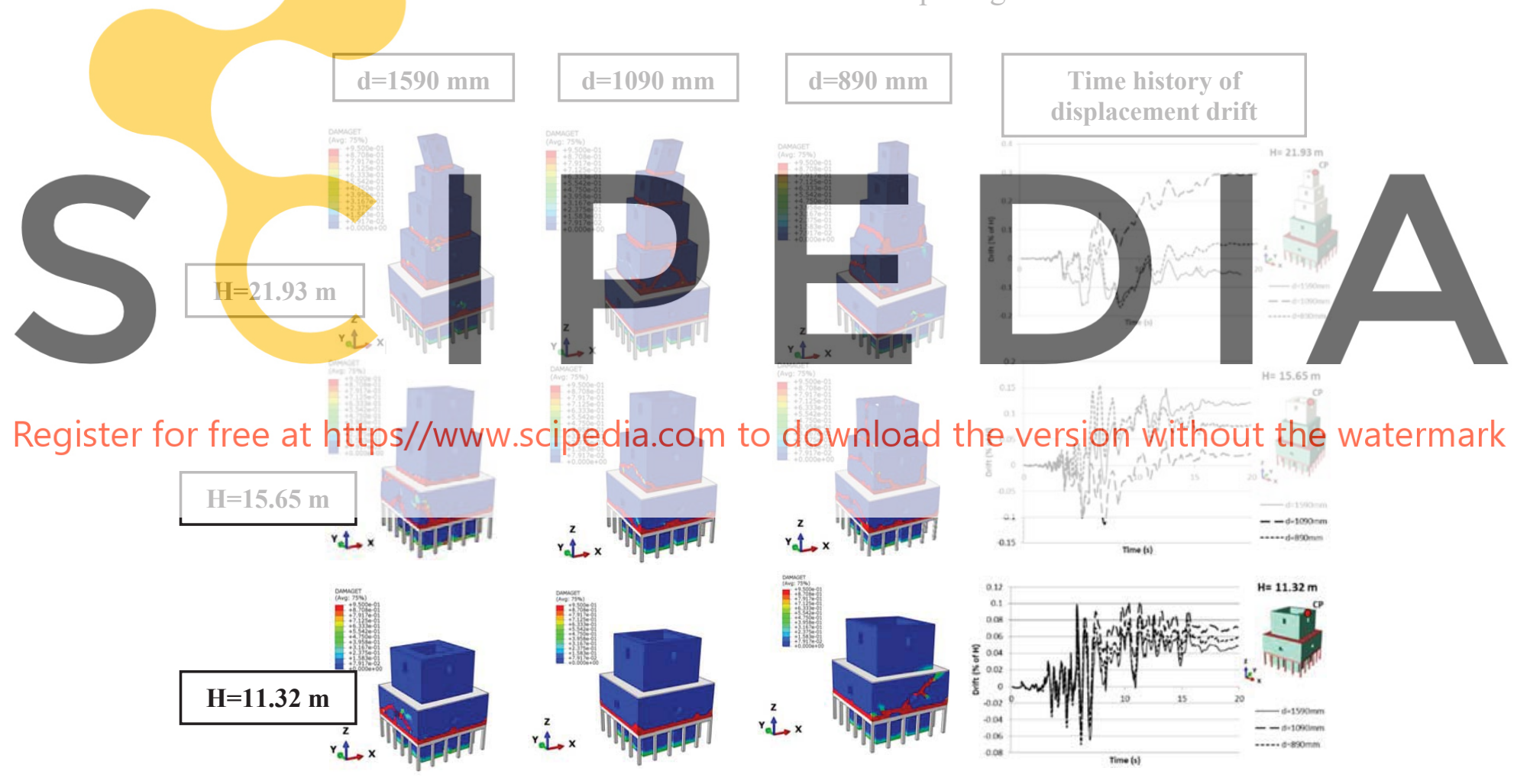

Figure 9 - Final tensile damage patterns and time history of displacement drift of the control points for Nyatopol temple with varied thickness $\mathrm{d}=1590 \mathrm{~mm}, \mathrm{~d}=1090 \mathrm{~mm}$ and $\mathrm{d}=890 \mathrm{~mm}$ at the ground floor and varied height $\mathrm{H}=21.93 \mathrm{~m}, \mathrm{H}=15.65 \mathrm{~m}$ and $\mathrm{H}=11.3 \mathrm{~m}$

If strengthening measures are not already applied, the assumption of box-like behavior including metal plates at the top of corners of external walls cannot be presupposed. 


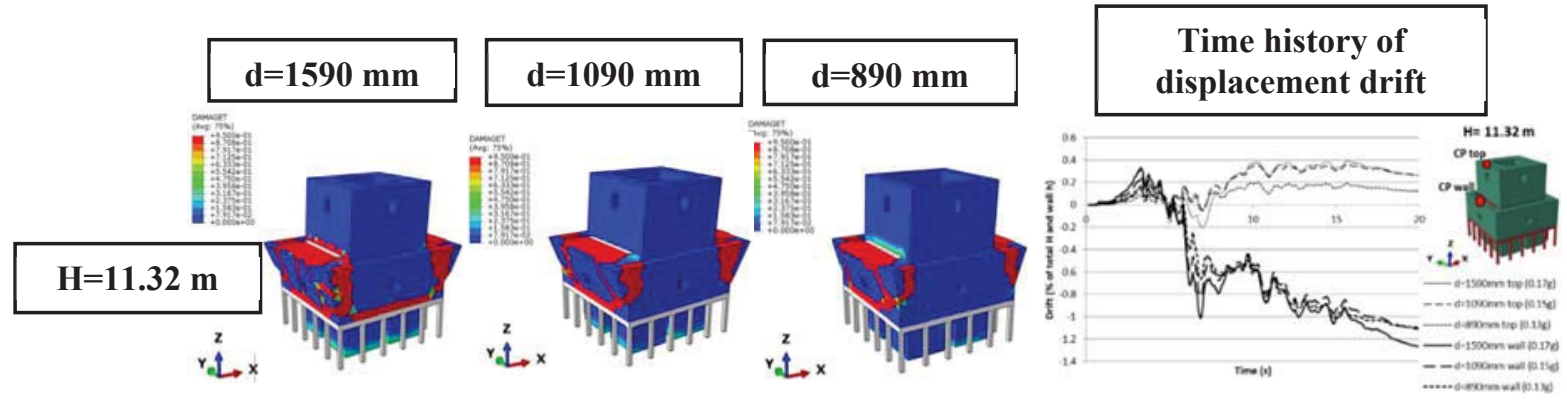

Figure 10 - Final tensile damage patterns and time history of relative drift of the control points for Nyatopol temple with $\mathrm{H}=11.32 \mathrm{~m}$ with flexible floor assumption

In that case, another modeling approach was applied, which rendered out-of-plane overturning of external walls, especially when stocky structures were at stake. In other words, when slenderness was higher (e.g. Gopinath temple with $\mathrm{H}=18.54 \mathrm{~m}$ ) the structure behaved similarly to towers (flexural hinge occurs), while when the slenderness was smaller (e.g. Nyatopol temple with $\mathrm{H}=11.32 \mathrm{~m}$ ) collapse mechanisms include out-of-plane overturning of external walls perpendicular to ground motion actions and the loss of interlocking between perpendicular walls was evident at both (see Figure 10).

\section{CONCLUSIONS}

In this study, the seismic performance of old multi-tiered temples in Nepal were assessed using different computational approaches including: a) linear; b) nonlinear static; and c) nonlinear dynamic analyses. A sensitivity study was also undertaken to investigate the influence of wall thickness and height of Nepalese temples on their seismic behavior. A series of macromodels based on the finite element method of analysis were developed. Masonry has been modeled based on the Concrete Damaged Plasticity Model (CDPM) available in ABAQUS.

Comparative damage analysis shows that the selection of the suitable approach for modelling such structures is critical to avoid misleading information about their seismic performance. NLDA shows that pyramidal configuration with progressive reduction of cross section at each floor activates more shear resistance in its behavior than the flexural one. Application of nonlinear static analysis thus is not justified since its results are in principle more oriented to flexural than to shear behavior, which is not in correspondence with the most accurate NLDA for this type of structures. Correct assessment of failure modes is essential for proper design of intervention strategy which is necessary to be done for many temples.

Under the assumption of stiff floor, failure mechanisms do not change in the case of the most slender temples among all investigated (Gopinath temples with $\mathrm{H}=18.54 \mathrm{~m}$ with varied thickness) comparing to the case of flexible floor. In the case of the stockiest temples (Nyatopol temples with $\mathrm{H}=11.32 \mathrm{~m}$ ) the failure mechanism is reached only when flexible floor is assumed. Being closer to reality, it is evident that overturning of the external walls takes place. In order to avoid this proper strengthening measures are necessary to be applied. 
Acknowledgement. The authors would like to acknowledge the funding received from British Academy's Global Challenges Research Fund: Cities and Infrastructure Program to carry out the research titled 'Reducing Disaster Risk to Life and Livelihoods by Evaluating the Seismic Safety of Kathmandu's Historic Urban Infrastructure' (CI70241) and the generous logistical support offered by the Pashupati Area Development Trust and the Department of Archaeology, Government of Nepal.

\section{REFERENCES}

[1] M. Betti, A. Borghini, S. Boschi, A. Ciavattone and A. Vignoli, "Comparative Seismic Risk Assessment of Basilica-type Churches," Journal of Earthquake Engineering, 22:sup1, 62-95, DOI: 10.1080/13632469.2017.1309602, 2018.

[2] V. Sarhosis, G. Milani, A. Formisano and F. Fabbrocino, "Evaluation of different approaches for the estimation of the seismic vulnerability of masonry towers," Bull Earthquake Eng (2018) 16:1511-1545.

[3] M. Valente and G. Milani, "Effects of Geometrical Features on the Seismic Response of Historical Masonry Towers," Journal of Earthquake Engineering, 22:sup1, 2-34, DOI: 10.1080/13632469.2016.1277438, 2018.

[4] A. M. D’Altri, G. Castellazzi and S. Miranda, "Collapse investigation of the Arquata del Tronto medieval fortress after the 2016 Central Italy seismic sequence," Journal of Building Engineering 18 (2018) 245-251.

[5] J. Bijaya, R. Wei-Xin, Z. Zhou-Hong and M. Prem Nath, "Dynamic and seismic performance of old multi-tiered temples in Nepal," Engineering Structures 25 (2003) 1827-1839, 11 August 2003.

[6] A. Arce, P. Awal and A. Tamrakar, "Structural analysis and strengthening proposals for the Gopinath temple in Kathamndu Durbar Square," January 2018.

[7] D. Sonda, D. Bothara, C. Chesi, V. Sumini and e. al, "ANALYSIS OF THE SEISMIC PERFORMANCE OF A STRENGTHENED PAGODA TEMPLE DURING GORKHA EARTHQUAKE," in 16th World Conference on Earthquake, 16WCEE 2017, Santiago Chile, January 9th to 13th 2017.

[8] P. Grassl, D. Xenos, U. Nystrom, R. Rempling and K. Gylltoft, "CDPM2: A damageplasticity approach to modelling the failure of concrete," 26 Jul 2013.

[9] G. Milani and M. Valente, "Failure analysis of seven masonry churches severely damaged during the 2012 Emilia-Romagna (Italy) earthquake: Non-linear dynamic analyses vs conventional static approaches," Engineering Failure Analysis 54 (2015) 13-56, 31 March 2015.

[10] " Direttiva del Presidente del Consiglio dei Ministri - Valutazione e riduzione del rischio sismico del patrimonio culturale con riferimento alle Norme techice per le construzioni di cui al D.M. 14/01/2018," p. 29, 9 Febbraio 2011. 